\title{
EXTRACTION EQUILIBRIUM OF COPPER BY VERSATIC ACID
}

\author{
KATSUTOSHI INOUE, HiRONORI AMANO, YOSHIHIRo YAYAMA \\ AND ISSEI NAKAMORI \\ Department of Industrial Chemistry, Saga University, Saga 840
}

\begin{abstract}
The distribution equilibrium in the solvent extraction of copper (II) by $n$-hexane solution of Versatic 10, a commercial carboxylic acid produced by Shell Chemical Co. Ltd., from nitrate medium was measured at $30^{\circ} \mathrm{C}$. The stoichiometric relation in this copper extraction reaction was found to be expressed as follows.

$$
2 \mathrm{Cu}_{\mathrm{aq}}^{2+}+3 \mathrm{H}_{2} \mathrm{R}_{2 \circ \mathrm{rg} .} \rightleftharpoons\left(\mathrm{CuR}_{2} \cdot \mathrm{HR}\right)_{2 \circ \mathrm{rg} .}+4 \mathrm{H}_{\mathrm{aq}}^{+} . \quad K_{\mathrm{q}}
$$

where the equilibrium constant was determined as $K_{\mathrm{e}}=1.10 \times 10^{-13}$.

Also, the aqueous solubility of Versatic 10, which is an indispensable datum for the economic evaluation of the commercial-scale extraction, was measured and was interpreted quantitatively in terms of the following two equilibria.

$$
\begin{array}{ll}
\mathbf{H}_{2} \mathbf{R}_{20 \mathrm{rg} .} \rightleftharpoons \mathbf{2} \mathbf{H R}_{\mathrm{aq} .} & K_{1} \\
\mathbf{H R}_{\mathrm{aq} .} \rightleftharpoons \mathbf{H}_{\mathrm{aq} .}^{+}+\mathbf{R}_{\mathrm{aq} .}^{-} & K_{2}
\end{array}
$$

where the equilibrium constants, $K_{1}$ and $K_{2}$ were found to be $9.6 \times 10^{-7} \mathrm{~mol} / l$ and $1.1 \times 10^{-6} \mathrm{~mol} / l$, respectively.
\end{abstract}

\section{Introduction}

Carboxylic acids have been in extensive use as extractants for various kinds of metals for many years in the field of analytical chemistry and several review papers on this theme have been published ${ }^{3,5,6,9,11}$.

In recent years, Versatic acid and naphthenic acid, which can be obtained in large quantities and at moderate prices as by-products of the petroleum industry, have begun to be used for the purification of such metals as copper, nickel, cobalt and rare earth elements in the field of hydrometallurgy. Consequently, there have been many publications on the extraction equilibrium of metals with these commercial carboxylic acids, especially on the extraction equilibrium of copper with Versatic acid.

Versatic acid, produced by Shell Chemical Co. Ltd., is a mixture of aliphatic, mainly tertiary, $C_{9}$ to $C_{11}$ monocarboxylic acids having the general structure<smiles>[R]C([R])(C)C(=O)O</smiles>

where $R_{1}$ and $R_{2}$ are in the range of $C_{3}-C_{4}$ for Versatic 9-11 and $R_{1}+R_{2}=C_{7}$ for Versatic 10, respectively.

Ashbrook ${ }^{2}$ reported the effect of free ammonia on the distribution ratio of copper in the extraction from

Received July 6, 1979. Correspondence concerning this article should be addressed to $K$. Ionoue. H. Amano is now with Toshiba Silicon Co., Ltd., O'ta 373 and Y. Yayama is now with VIVO Foods Co., Ltd., Fukuoka 812. sulphate medium with Versatic 9-11.

Shibata and Nishimura ${ }^{10,12-15)}$ clarified the composition of the complex extracted from nitrate medium with benzene solution of Versatic 9-11 and further investigated the effects of such factors as sulphate and chloride ions, ammonium salts and temperature on the distribution equilibrium. Also, Lee and $\mathrm{Kim}^{7,8)}$ studied the extraction equilibrium from sulphate and nitrate media with benzene solution of Versatic 10, which is a newly developed Versatic acid having a narrower molecular weight distribution than Versatic 9-11 mentioned above and having the following properties: acid value $[\mathrm{mg} \mathrm{KOH} / \mathrm{g}]=323$, purity $[\mathrm{wt} \%]=$ 99 , specific gravity at $25^{\circ} \mathrm{C}=0.91$.

Most of these studies were made only for the extraction equilibrium in a lower concentration range of copper in the organic phase, and studies over wider ranges of copper-loading to Versatic acid are few.

To obtain fundamental information for the kinetic investigation of this extraction system, the present study was carried out on the distribution equilibrium of copper between aqueous ammonium nitrate solution and $n$-hexane solution of Versatic 10 to investigate the dependence on the concentrations of copper and hydrogen ions in the aqueous phase and that of Versatic 10 in the organic phase over a wider range of loading ratio from $7 \times 10^{-4}$ up to $2 \times 10^{-1}$.

It is of great importance to obtain some knowledge of the aqueous solubility of Versatic acid for the evaluation of the economy of extraction in a commer- 
cial-scale plant. Unfortunately, there has been no information of this kind except qualitative data on the solubility of Versatic 9-11 in aqueous ammonium sulphate solution ${ }^{11}$. Hence, the aqueous solubility of Versatic 10 was also measured and interpreted quantitatively in the present study.

\section{Theory}

\section{1 Equilibrium distribution of copper}

The stoichiometric relation in the extraction of divalent metals such as $\mathrm{Cu}$ (II) by carboxylic acids is described in general form ${ }^{16)}$ as:

$$
\begin{aligned}
& x \mathrm{M}_{\mathrm{aq} .}^{2+}+x(1+n / 2) \mathrm{H}_{2} \mathrm{R}_{2 o r g} . \\
& =\left(\mathrm{MR}_{2} \cdot n \mathrm{HR}\right)_{x \circ \mathrm{rg} .}+2 x \mathrm{H}_{\mathrm{aq} .}^{+} \quad K_{\mathrm{e}}
\end{aligned}
$$

where $x$ and $n$ denote the degree of aggregation of extracted species in the organic phase and the number of solvated carboxylic acid molecules in the extracted species, respectively. HR denotes the carboxylic acid, the extractant, and it is considered to exist as the dimeric species $\left(\mathrm{H}_{2} \mathrm{R}_{2}\right)$ in such a nonpolar diluent as $n$-hexane.

The equilibrium constant $K_{\mathrm{e}}$ for the above reaction is described as

$$
K_{\mathrm{e}}=\frac{\left[\left(\mathrm{MR}_{2}^{-} \cdot n \mathrm{HR}\right)\right]_{x}\left[\mathrm{H}^{+}\right]^{2 x}}{\left[\mathrm{M}^{2+}\right]^{x}\left[\mathrm{H}_{2} \mathrm{R}_{2}\right]^{x(1+x / 2}}
$$

The total concentration of the metal in the organic phase is expressed as

$$
C_{\mathrm{AO}}=\sum_{x=1}^{\mathrm{X}} \sum_{n=0}^{\mathrm{N}} x\left[\left(\mathrm{MR}_{2} \cdot n \mathrm{HR}\right)_{x}\right]
$$

where $\mathrm{X}$ and $\mathrm{N}$ denote the maximum numbers of $x$ and $n$, respectively.

For simplicity of further treatment, only a single extracted species was considered in the organic phase, i.e.

$$
C_{\mathrm{AO}}=x\left[(\overline{\mathrm{MR}} \cdot n \mathrm{HR})_{x}\right]=x K_{\mathrm{e}}\left[\mathrm{M}^{2+}\right]^{x}\left[\mathrm{H}_{2} \mathrm{R}_{2}\right]^{x(1+n / 2)} /\left[\mathrm{H}^{+}\right]^{2 x}
$$

Meanwhile, in the aqueous solution containing ammonia, the presence of the divalent metal ions capable of forming complexes with ammonia will give rise to the formation of ammine complexes as follows.

$$
\mathrm{M}_{\mathrm{aq} .}^{2+}+i \mathrm{NH}_{3 \mathrm{aq} .} \rightleftharpoons \mathrm{M}\left(\mathrm{NH}_{3}\right)_{i \mathrm{aq} .}^{2+} \quad \beta_{i}(i=1-4)
$$

where $\beta_{i}$ denotes the $i$-th metal ammine formation constant and the values of $\beta_{1}-\beta_{4}$ are as follows ${ }^{4}$.

$$
\begin{array}{ll}
\beta_{1}=1.35 \times 10^{4} & {[l / \mathrm{mol}]} \\
\beta_{2}=4.1 \times 10^{7} & {\left[(l / \mathrm{mol})^{2}\right]} \\
\beta_{3}=3.0 \times 10^{20} & {\left[(l / \mathrm{mol})^{3}\right]} \\
\beta_{4}=3.9 \times 10^{12} & {\left[(l / \mathrm{mol})^{4}\right]}
\end{array}
$$

Consequently, $\left[\mathrm{M}^{2+}\right]$ is described by the total concentration of the metal in the aqueous phase $\left(C_{\mathrm{AW}}\right)$ and free ammonia concentration as follows.

$$
\left[\mathrm{M}^{2+}\right]=C_{\mathrm{AW}} /\left(1+\sum_{i=1}^{4} \beta_{i}\left[\mathrm{NH}_{3}\right]^{i}\right)
$$

Furthermore, the concentration of free ammonia is correlated to that of ammonium ion through the equilibrium relation described as follows.

$$
\mathrm{NH}_{4 \mathrm{aq} .}^{+} \rightleftharpoons \mathrm{NH}_{3 \mathrm{aq} .}+\mathrm{H}_{\mathrm{aqq}}^{+} . \quad K_{\mathrm{A}}
$$

where $K_{\mathrm{A}}=5.5 \times 10^{-10}[\mathrm{~mol} / \mathrm{l}]^{4}$.

Electroneutrality in the aqueous phase gives Eq. (8).

$$
2 C_{\mathrm{AW}}+\left[\mathrm{H}^{+}\right]+\left[\mathrm{NH}_{4}^{+}\right]=\left[\mathrm{OH}^{-}\right]+\left[\mathrm{NO}_{3}^{-}\right]
$$

Under conditions where $C_{\mathrm{Aw}}$ is low enough compared to ammonium nitrate concentration, and where $\mathrm{pH}$ is neither too low nor too high, Eq. (8) can be approximated as

$$
\left[\mathrm{NH}_{4}^{+}\right]=\left[\mathrm{NO}_{3}^{-}\right]
$$

Ultimately, Eq. (6) is reduced to Eq. (10), taking account of Eq. (9) and the equilibrium relation, Eq. (7).

$$
\left[\mathrm{M}^{2+}\right]=C_{\mathrm{AW}} /\left(1+\sum_{i=1}^{4} \beta_{i}^{\prime} /\left[\mathrm{H}^{+}\right]^{i}\right)
$$

where

$$
\beta_{i}^{\prime}=\beta_{i}\left(K_{\mathrm{A}}\left[\mathrm{NO}_{3}^{-}\right]\right)^{i}
$$

Substitution of Eq. (10) in Eq. (4) followed by rearrangement gives the loading ratio, the ratio of the equilibrium concentration of the metal in the organic phase $\left(C_{\mathrm{Ao}}\right)$ to the total concentration of the carboxylic acid in the organic phase $\left(C_{B \text { org. }}\right)$, for given values of $C_{\mathrm{Borg}}, C_{\mathrm{Aw}}$ and $\mathrm{pH}$ as follows.

$$
\begin{aligned}
\frac{C_{\mathrm{AO}}}{C_{\mathrm{Borg} .}}= & x K_{\mathrm{e}} \cdot C_{\text {Borg. }}^{(\text {rno } / 2-1)} \cdot\left\{C_{\mathrm{A} W} C_{\mathrm{Borg} .} /\left[\mathrm{H}^{+}\right]^{2}\right. \\
& \left.\times\left(1+\sum_{i=1}^{4} \beta_{i}^{\prime} /\left[\mathrm{H}^{+}\right]^{i}\right)\right\}^{\infty} \cdot\left\{\left[\mathrm{H}_{2} \mathrm{R}_{2}\right] / C_{\mathrm{Borg} .}\right\}^{x(1+n / 2)}
\end{aligned}
$$

In Eq. (12), $\left[\mathrm{H}_{2} \overline{\mathrm{R}}_{2}\right] / C_{\mathrm{Borg} \text {. }}$ is given for a corresponding value of $C_{\mathrm{Borg}}^{(n x / 2-1)} \cdot\left\{C_{\mathrm{Aw}} C_{\mathrm{Borg} .} /\left[\mathrm{H}^{+}\right]^{2}\left(1+\sum_{i=1}^{4} \beta_{i}^{\prime}\left[\left[\mathrm{H}^{+}\right]^{i}\right)\right\}^{x}\right.$ as a solution of the $x(1+n / 2)$-th order nonlinear equation described by Eq. (13), which is derived from the material balance of the carboxylic acid.

$$
\begin{aligned}
& x(2+n) \cdot K_{\mathrm{e}} \cdot\left\{C_{\mathrm{AW}} C_{\mathrm{Borg} .} /\left[\mathrm{H}^{+}\right]^{2}\left(1+\sum_{i=1}^{4} \beta_{i}^{\prime} /\left[\mathrm{H}^{+}\right]^{i}\right)\right\}^{x} \\
& \quad \times C_{\mathrm{Borg}}^{(n x / 2)-1}\left\{\left[\mathrm{H}_{2} \mathrm{R}_{2}\right] / C_{\mathrm{Borg}} .\right\}^{x(1+n / 2)} \\
& \quad+2\left\{\left[\mathrm{H}_{2} \mathrm{R}_{2}\right] / C_{\mathrm{Borg} .}\right\}-1=0
\end{aligned}
$$

So far, it is conventional to express the equilibrium relations in the extraction of divalent metals by carboxylic acids in terms of the plot of $C_{\mathrm{AO}}$ against $C_{\mathrm{AW}}$ / $\left[\mathrm{H}^{+}\right]^{2}$ for various values of $C_{\mathrm{B} \circ \mathrm{rg} \text {. }}$ as a parameter ${ }^{16)}$. However, the equilibrium expression mentioned above is reasonable only in the lower range of the loading ratio where the free species of the carboxylic acid is predominant in the organic phase. On the contrary, Eqs. (12) and (13) can express the equilibrium relation over a wider range of the loading ratio. 


\subsection{Aqueous solubility of carboxylic acid}

The distribution of carboxylic acid in the aqueous phase under the condition free from copper ion is described by physical partition into the aqueous phase followed by dissociation into a proton and a carboxylic anion:

$$
\begin{aligned}
& \mathrm{H}_{2} \mathrm{R}_{\mathrm{arg} .} \rightleftharpoons 2 \mathrm{HR}_{\mathrm{aq} .} \quad K_{1} \\
& \mathrm{HR}_{\mathrm{aq} .} \rightleftharpoons \mathrm{H}_{\mathrm{aq} .}^{+}+\mathrm{R}_{\mathrm{aq}}^{-} . \quad K_{2}
\end{aligned}
$$

Accordingly, the total concentration of carboxylic acid in the aqueous phase $\left(C_{\mathrm{Baq}}\right)$ is expressed as follows.

$$
\begin{aligned}
C_{\text {Baq. }} & =[\mathrm{HR}]+\left[\mathrm{R}^{-}\right] \\
& =\left\{1+K_{2} /\left[\mathrm{H}^{+}\right]\right\} \cdot\left(K_{1}\left[\overline{\mathrm{H}_{2} \mathrm{R}_{2}}\right]^{1 / 2}\right.
\end{aligned}
$$

On the other hand, material balance of carboxylic acid gives

$$
\begin{aligned}
V_{\text {org. }} C_{\mathrm{B} 0} & =V_{\text {org. }} C_{\mathrm{Borg} .}+V_{\mathrm{aq} .} C_{\mathrm{Baq} .} \\
& =2 V_{\text {org. }}\left[\mathrm{H}_{2} \mathrm{R}_{2}\right]+V_{\mathrm{aq} .} C_{\mathrm{Baq} .}
\end{aligned}
$$

where $C_{\mathrm{B} 0}$ is the initial concentration of carboxylic acid in the organic phase.

Ultimately, $C_{\mathrm{Baq}}$. is correlated to $C_{\mathrm{B} 0}$ and $\left[\mathrm{H}^{+}\right]$as follows.

$$
C_{\mathrm{Baq} .}^{\mathrm{a}} /\left\{C_{\mathrm{B} 0}-\left(V_{\mathrm{aq} .} / V_{\text {org. }}\right) \cdot C_{\mathrm{Baq} .}\right\}=\frac{1}{2} K_{1}\left\{1+K_{2} /\left[\mathrm{H}^{+}\right]\right\}^{2}
$$

\section{Experimental}

Versatic 10 donated by Shell Chemical Co. Ltd. was used after dilution with $n$-hexane to the required concentration without further purification.

The aqueous copper solution was prepared by dissolution of copper nitrate into $1 \mathrm{~mol} / \mathrm{l}$ aqueous ammonium nitrate solution in order to keep the ionic strength constant. In addition, a small amount of ammonia was added to adjust $\mathrm{pH}$.

Firstly, equilibrium distribution of copper was measured at $30^{\circ} \mathrm{C}$ under various conditions: the concentration of Versatic 10 in the organic phase was $0.10-0.98 \mathrm{~mol} / \mathrm{l}$, initial concentration of copper in the aqueous phase was $1.1 \times 10^{-3}-3.3 \times 10^{-2} \mathrm{~mol} / l$ and $\mathrm{pH}$ ranged from 3.7 to 5.8. Equal volumes of the aqueous and organic phases of known concentrations were shaken in a flask and allowed to attain equilibrium in a thermostat-bath. After about 12 hours, the two phases were separated and analysed for copper content.

The concentration of Versatic 10 in the organic phase was determined by titration with ethanol solution of potassium hydroxide and phenolphthalein as indicator. Copper content in the aqueous phase was determined by titration with EDTA and PAN as indicator. The concentration of copper in the organic phase was estimated by mass balance of the copper content in the aqueous phase.

Secondly, aqueous solubility of Versatic 10 under

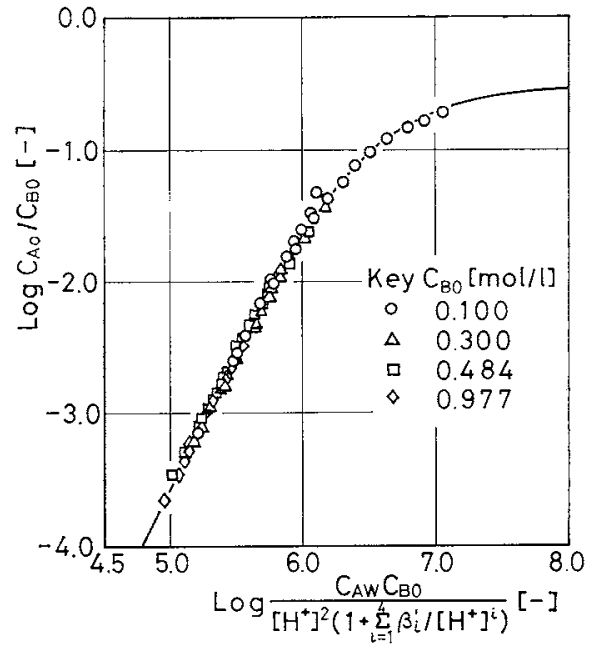

Fig. 1 Distribution equilibrium of copper between aqueous ammonium nitrate-ammonia mixture and $n$-hexane solution of Versatic $\mathbf{1 0}$

the condition free from copper ion was measured at $30^{\circ} \mathrm{C}$ under various conditions: initial concentration of Versatic 10 in the organic phase was $5.2 \times 10^{-2}-1.18 \times$ $10^{\circ} \mathrm{mol} / l$ and $\mathrm{pH}$ range was $4-9$. The procedure was the same for measurement of the distribution of copper. The equilibrium concentration of Versatic 10 in the aqueous phase was estimated by mass balance of Versatic 10 content in the organic phase before and after equilibration in the higher $\mathrm{pH}$ region. On the other hand, in the lower $\mathrm{pH}$ region, it was determined using the Nippon Bunko Model 524 total and organic carbon analyser of Oita University, with which the total organic carbon concentration in the aqueous phase can be determined by infrared absorption spectrochemical analysis as the concentration of carbon dioxide issued from the complete oxidation of the organic carbon in the aqueous phase.

\section{Results and Discussion}

\section{1 Equilibrium distribution of copper}

First of all, the equilibrium concentration of copper in the organic phase was correlated to that in the aqueous phase, total concentration of Versatic 10 and hydrogen ion concentration based on Eqs. (12) and (13) assuming that the concentration of Versatic 10 in the aqueous phase after equilibration can be ignored compared to its initial concentration in the organic phase, i.e. $C_{\mathrm{Borg}} \simeq C_{\mathrm{B} 0}$. That is, $\log \left(C_{\mathrm{A} 0} / C_{\mathrm{B} 0}\right)$ was plotted against $\log \left[C_{\mathrm{AW}} C_{\mathrm{B} 0} /\left\{\left[\mathrm{H}^{+}\right]^{2}\left(1+\sum_{i=1}^{4} \beta_{i}^{\prime} /\left[\mathrm{H}^{+}\right]^{i}\right)\right\}\right]$ for various values of $C_{\mathrm{B} 0}$ as shown in Fig. 1. From Fig. 1, all of the plotted points lie on a single curve regardless of $C_{\mathrm{B} 0}$ and this curve approaches a rectilinear line of which slope is equal to 2 in the lower region of $C_{\mathrm{A} O} / C_{\mathrm{B} 0}$.

Provided that $C_{\mathrm{Borg} .} \simeq C_{\mathrm{B} 0}$ and, in addition, in the lower region of $C_{\mathrm{A} 0} / C_{\mathrm{B} 0}$, logarithm of Eq. (12) gives 


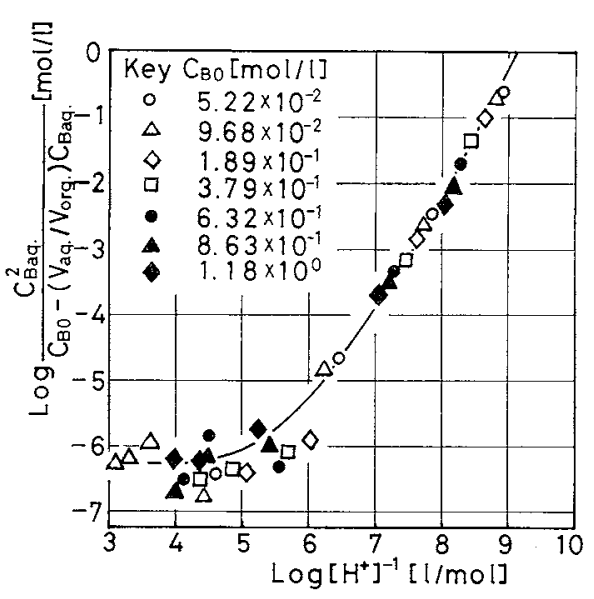

Fig. 2 Aqueous solubility of Versatic 10

$$
\begin{aligned}
& \log \left(C_{\mathrm{A} 0} / C_{\mathrm{B} 0}\right) \simeq \log \left(x K_{\mathrm{e}}\right)+(n x / 2-1) \cdot \log C_{\mathrm{B} 0} \\
& +x \cdot \log \left\{C_{\mathrm{AW}} C_{\mathrm{B} 0} /\left[\mathrm{H}^{+}\right]^{2}\left(1+\sum_{i=1}^{4} \beta_{i}^{\prime} /\left[\mathrm{H}^{+}\right]^{i}\right)\right\} \\
& +x(1+n / 2) \cdot \log (1 / 2)\}
\end{aligned}
$$

According to Eq. (19), it is obvious that the former fact mentioned above indicates that $n x=2$. On the other hand, the latter indicates that $x=2$ and therefore $n=1$. Consequently, the stoichiometric relation for this extraction reaction is described as

$$
2 \mathrm{Cu}_{\mathrm{aq} .}^{2+}+3 \mathrm{H}_{2} \mathrm{R}_{2 \text { org. }} \rightleftharpoons\left(\mathrm{CuR}_{2} \cdot \mathrm{HR}\right)_{2 \text { org. }}+4 \mathrm{H}_{\mathrm{aq}}^{+} \text {. }
$$

The equilibrium constant for this reaction is estimated from the value at which the rectilinear line in Fig. 1 intersects the ordinate based on Eq. (19) as $K_{\mathrm{e}}=$ $1.10 \times 10^{-13}$. This value is somewhat smaller than $2.24 \times 10^{-13}$ for the extraction from sulphate medium by benzene solution of Versatic $10^{7}$ and $2.00 \times 10^{-13}$ for the extraction from nitrate medium by benzene solution of Versatic 9-11 ${ }^{13)}$ though the stoichiometric relation described by Eq. (20) is the same as those proposed by these investigators.

The solid line in Fig. 1 is the calculated result obtained by Eqs. (12) and (13) using the value of $x, n$ and $K_{\mathrm{e}}$ evaluated in the manner mentioned above.

\section{2 Aqueous solubility of Versatic $\mathbf{1 0}$}

The total concentration of Versatic 10 in the aqueous phase is shown in Fig. 2 according to Eq. (18). The points in the figure lie on a straight line of slope 2 in the higher $\mathrm{pH}$ region, as expected from Eq. (18). On the other hand, the values of the ordinate in Fig. 2 seems to be constant irrespective of $\mathrm{pH}$ in the lower $\mathrm{pH}$ region, also as expected from Eq. (18), though there is considerable scattering.

The values of $K_{1}$ and $K_{2}$ in Eq. (18) which give minimum standard deviation between the experimental and calculated results were evaluated as $K_{1}=9.6 \times$ $10^{-7} \mathrm{~mol} / l$ and $K_{2}=1.1 \times 10^{-6} \mathrm{~mol} / l$. The solid line in Fig. 2 is the calculated result by Eq. (18) using these values.

\section{Conclusion}

The equilibrium distribution of copper between the aqueous ammonium nitrate-ammonia mixture and $n$ hexane solution of Versatic 10 , a tertiary monocarboxylic acid, was studied and the effects of the concentrations of Versatic 10 in the organic phase and copper and hydrogen ions in the aqueous phase on the distribution equilibrium were clarified.

It was found that the copper ion is extracted by Versatic 10 according to the following stoichiometric relation.

$$
2 \mathrm{Cu}_{\mathrm{aq} .}^{2+}+3 \mathrm{H}_{2} \mathrm{R}_{\text {2org. }} \rightleftharpoons\left(\mathrm{CuR}_{2} \cdot \mathrm{HR}\right)_{20 \mathrm{rg} .}+4 \mathrm{H}_{\mathrm{aq} .}^{+} . \quad K_{\mathrm{e}}
$$

The equilibrium constant for this reaction was evaluated as $K_{\mathrm{e}}=1.10 \times 10^{-18}$.

Aqueous solubility of Versatic 10 was also investigated and explained, taking account of the physical partition of Versatic 10 into the aqueous phase followed by its dissociation as follows.

$$
\begin{array}{ll}
\mathrm{H}_{2} \mathrm{R}_{\text {2org. }} \rightleftharpoons 2 \mathrm{HR}_{\mathrm{aq} .} & K_{\mathrm{t}} \\
\mathrm{HR}_{\mathrm{aq} .} \rightleftharpoons \mathrm{H}_{\mathrm{aq} .}^{+}+\mathrm{R}_{\mathrm{aq} .}^{-} . & K_{2}
\end{array}
$$

The equilibrium constants for the above reactions were evaluated as $K_{1}=9.6 \times 10^{-7} \mathrm{~mol} / l$ and $K_{2}=$ $1.1 \times 10^{-6} \mathrm{~mol} / \mathrm{l}$.

\section{Acknowledgment}

The authors are deeply indebted to Shell Chemical Co. Ltd. for supply of the sample of Versatic 10 and to Associate Professor T. Hano of Oita University for allowing the authors to use the total and organic carbon analyser. The authors also acknowledge financial support from a grant-in-aid for fundamental scientific research, Ministry of Education, Japan.

$$
\begin{aligned}
& \text { Nomenclature } \\
& C_{\mathrm{A} 0}=\text { total concentration of metal extracted into } \\
& \text { the organic phase [mol/l] } \\
& C_{\mathrm{Aw}}=\text { total concentration of metal in the aqueous } \\
& \text { phase } \\
& C_{\mathrm{Brq}} . \quad=\text { total concentration of carboxylic acid in } \\
& \text { the aqueous phase }[\mathrm{mol} / l]
\end{aligned}
$$

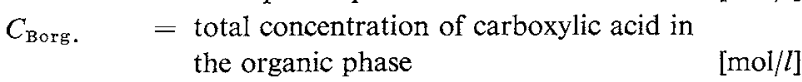

$$
\begin{aligned}
& \begin{aligned}
C_{\mathrm{BO}}= & \text { initial concentration of carboxylic acid } \\
& \text { in the organic phase } \\
& {[\mathrm{mol} / \mathrm{l}] }
\end{aligned} \\
& \mathrm{HR}=\text { monomeric species of carboxylic acid } \\
& \mathrm{H}_{2} \mathrm{R}_{2} \quad=\text { dimeric species of carboxylic acid } \\
& K_{\mathrm{A}}=\text { dissociation constant of ammonium ion }[\mathrm{mol} / l] \\
& K_{\mathrm{e}} \quad=\text { equilibrium constant for the extraction } \\
& \text { reaction of metal by carboxylic acid [-] } \\
& K_{1}=\begin{array}{l}
\text { partition constant of carboxylic acid into } \\
\text { the aqueous phase } \\
{[\mathrm{mol} / l]}
\end{array} \\
& \begin{array}{lll}
K_{2} & =\text { dissociation constant of carboxylic acid } \\
& \text { in the aqueous phase } &
\end{array} \\
& \mathrm{M}^{2+}=\text { species of divalent metal ion } \\
& \mathrm{M}\left(\mathrm{NH}_{3}\right)_{i}^{2+}=\text { species of } i \text {-th ammine complex of divalent } \\
& \text { metal ion } \\
& \mathrm{MR}_{2} \cdot n \mathrm{HR}=\text { species of metal complex extracted by } \\
& \text { carboxylic acid in the organic phase } \\
& \mathrm{N}=\text { maximum number of } n
\end{aligned}
$$




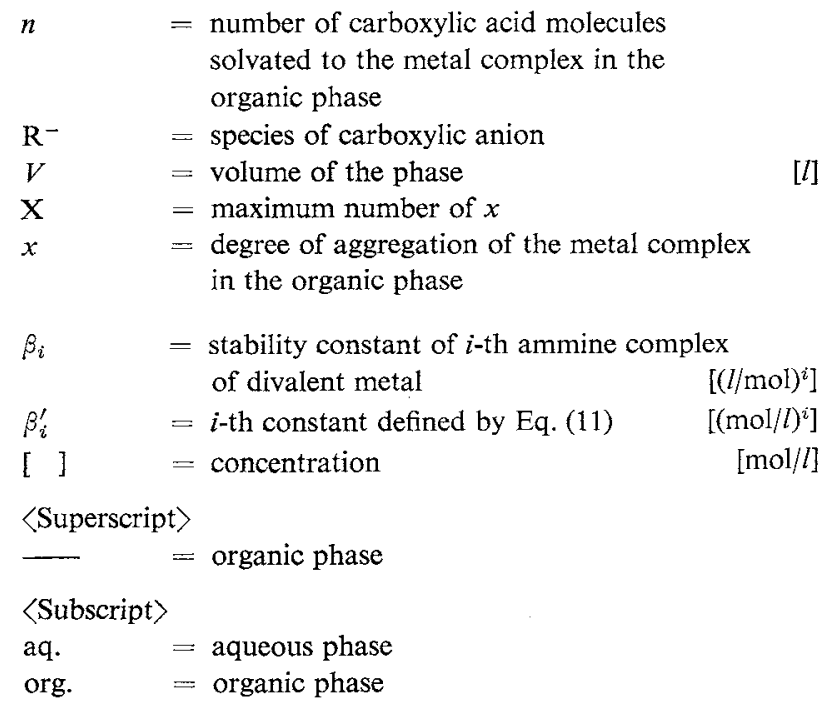

\section{Literature Cited}

1) Ashbrook, A. W.: J. Inorg. Nucl. Chem., 34, 1721 (1972).

2) idem: ibid., 34, 3523 (1972).
3) idem: Miner. Sci. Engng., 5, 169 (1973).

4) Bard, A. J.: "Yōekinai Ion Heikō", translated by Y. Matsuda and K. Ogura, Kagaku Dōjin, Kyoto (1975).

5) Fletcher, A. W. and D. S. Flett: "Solvent Extraction Chemistry of Metals", p. 359, Macmillan, London (1965).

6) Flett, D. S. and M. J. Jaycock: "Ion Exchange and Solvent Extraction", Vol. 3, p. 1, ed. by J. Marinsky and Y. Marcus, Marcel Dekker, New York (1973).

7) Lee, Dong Hwi and Soo Sik Kim: J. Korean Inst. Miner. Min. Engrs., 13, 246 (1976)

8) idem: ibid., 14, 203 (1977).

9) Miller, F.: Talanta, 21, 685 (1974).

10) Mukai, S., J. Shibata and S. Nishimura: Nippon Kinzoku Gakkaishi, 39, 976 (1975).

11) Rice, N. M.: Hydrometallurgy, 3, 111 (1978).

12) Shibata, J., T. Horiuchi, S. Tyoki and S. Nishimura: Nippon Kinzoku Gakkaishi, 38, 316 (1974).

13) Shibata, J. and S. Nishimura: ibid., 39, 206 (1975).

14) idem: Trans. Japan Inst. Metals, 18, 794 (1977).

15) Shibata, J., S. Nishimura and S. Mukai: Suiyo Kaishi, 18, 518 (1977).

16) Tanaka, M.: "Yōbai Chūshutsu no Kagaku", p.99, Baifūkan, Tokyo (1977). 